\title{
TEATRO DE RUA COMO OCUPAÇÃO DA CIDADE: CRIANDO COMUNIDADES TRANSITÓRIAS
}

\author{
André Carreira 1
}

Resumo

O presente texto apresenta uma reflexão sobre o teatro de rua como um teatro de ocupação da cidade e analisa procedimentos pelos quais essa modalidade teatral busca construir comunidades temporárias de espectadores e atores. O artigo faz referência às noções de ambiente urbano, repertórios de usos e jogo, relacionando estas com o fenômeno teatral que ocupa segmentos da cidade, supondo que a rua é um campo inóspito que o teatro busca ocupar como fala de resistência.

Palavras-chave: ambiente urbano, arte na rua, teatro e política.

\begin{abstract}
This article looks at street theatre as a theatre that takes the city, and it analyses procedures to construct temporary communities between spectators and actors. The text also presents the concepts of urban environment, use and game repertoires. These concepts are related to the resistant theatre that uses segments of the public space, and considers the street as a inhospitable field to be conquest.
\end{abstract}

Keywords: urban environment, art on streets, theatre and politics.

A reflexão sobre o teatro que se faz nas ruas nos conduz a uma inevitável aproximação com o fenômeno urbano e sua complexidade. Como sugere Nestor García Canclini em seu livro Imaginarios Urbanos (2005) dois aspectos do urbano aparecem como chaves neste contexto: a experiência de habitar a cidade e as representações que os habitantes fazem dessa cidade. A cidade é resultado da relação entre o habitar e sua construção imaginária.

O teatro de rua, especialmente, aquele que se caracteriza como de ocupação, é uma modalidade expressiva que discute a cidade como representação e interfere na mesma construindo formas alternativas de organização do espaço de modo fugaz. Isso pode ser associado às próprias características do urbano: fragmentação, fugacidade e sobreposição de falas sobre o espaço público como lugar sócio cultural.

${ }^{1}$ Diretor do grupo Experiência Subterrânea, Professor da UDESC, Pesquisador CNPq 
Um dos propósitos desse texto é refletir sobre as conformações momentâneas de comunidades que se dão ao redor do evento espetacular por força da interferência no espaço público. A ideia de uma comunidade temporária remete ao estabelecimento de vínculos momentâneos que determinam tomadas de decisões e compartilhamento de uma experiência que se dá no bojo da convivência com o espetáculo. Pensar essas comunidades transitórias é então realizar uma aproximação aos lugares e sentidos do teatro de rua como modalidade expressiva que ocupa o espaço público rompendo com os repertórios de usos instalados nos segmentos da cidade.

A formulação de uma comunidade momentânea se relaciona com a noção da cidade como algo que emerge das experiências de uso e fruição do espaço urbano. Neste sentido é interessante observar que Canclini afirma que:

Não somente fazemos a experiência física da cidade, não somente a percorremos e sentimos em nossos corpos o que significa caminhar tanto tempo ou viajar em pé em um ônibus, estar sob a chuva até que conseguimos um táxi, senão que imaginamos enquanto viajamos, construímos suposições sobre o que vemos, sobre quem cruza conosco, as zonas das cidade que desconhecemos e que temos que atravessar para chegar a outro destino, enfim o que nos acontece e aos outros na cidade. Grande parte do que nos acontece é imaginário, porque não surge de uma interação real. Toda interação tem uma quota de imaginário, mas ainda mais nestas interações evasivas e fugazes que propõe a metrópole. (2005, p. 89)

O olhar que imagina, fabrica a cidade. Ao mesmo tempo esse olhar produz os caminhos e circuitos que moldam a cidade que emerge do repertório de usos. A cidade imaginada, que também pode ser considerada como uma cidade narrada, tem uma força e presença fundamentais na estruturação do funcionamento cotidiano das ruas, dos lugares públicos onde essa cidade de materializa. As formas teatrais de rua, bem como outras manifestações parateatrais igualmente fornecem elementos que contribuem com a formulação de cidades imaginárias. Neste sentido, um teatro de ocupação se formula necessariamente como uma proposta que repensa esse imaginário que constitui a cidade como espaço desejado, sonhado, isto é, como um espaço a ser deformado pela ação da ficção.

Mas, essa cidade não é um objeto único e monolítico. Não há uma cidade unitária, uma cidade que se defina como uma totalidade perceptível que se possa abarcar de forma completa.

Quem conhece por inteiro uma grande cidade? Parece impossível abarcar a totalidade de uma cidade. Frente a essa percepção Canclini afirma 
que nos instalamos em micropólis e percorremos fragmentos de micropólis dos outros (2005, p. 111). Nossa "cidade" é de fato um segmento que percorremos e está definida pelo nosso repertório de usos, é a zona que ocupamos segundo nossas necessidades. Por isso, um teatro de ocupação não pode ter a pretensão de dialogar com toda a cidade, mas interfere de forma decisiva nos segmentos que ocupa e ali pode ter uma potência significativa, pois sua dimensão se definirá em relação aos limites - ainda que flexíveis e mutáveis - do respectivo segmento. Atuando nestes segmentos a dimensão espetáculo como fala que tensiona o espaços e desorganiza seus usos, adquire uma capacidade de diálogo mais amplo e intenso com esse contexto recortado da cidade.

Considerando a presença do teatro em zonas pode-se supor que existirá em uma determinada zona um importante número de cidadãos que serão usuários permanentes de tal zona. Assim, haverá possibilidades que os mesmos construam alguma forma de contato posterior à experiência do espetáculo, ou até compartilhem do evento espetacular reconhecendo no outro algum tipo de experiência compartilhada anterior.

Podemos pensar que a partir das interferências desse teatro nestas zonas se dão processos de resistência inerentes aos atritos existentes entre os usos pessoais e as normatizações do espaço público. Para Georg Simmel uma das características da modernidade, presente nas operações culturais da cidade, é a existência de elementos de resistência do sujeito a ser nivelado e consumido em um mecanismo técnico-social. (2005). Os discursos dos realizadores de teatro de rua geralmente aparecem associados com elementos de resistência cultural o que muitas vezes faz com esse teatro se caracterize como um "teatro político" ou como uma modalidade da "cultura popular". Mas, independente dos respectivos projetos políticos dos realizadores do teatro de rua, podese considerar que ao ocupar as ruas as linguagens da cena se fazem vozes políticas ativas pois decidem dialogar com normas, usos e procedimentos que definem o espaço como público.

O olhar agudo de Simmel sugere a percepção de uma cidade que modula o sujeito que resiste culturalmente, e esta resistência conformaria, ao mesmo tempo, o modelo de cidade no qual se vive. Assim, temos uma cidade que é um organismo de contradições e atritos, âmbito no qual predomina a busca pela satisfação de necessidades que nem sempre são percebidas de forma consciente. $\mathrm{O}$ tecido dos indivíduos se entrelaça mutuamente e a ação dos sujeitos em busca da satisfação das necessidades implica em deformações das estruturas coletivas, e no atrito com as normas institucionais. Simmel considera que "os problemas mais profundos da vida moderna brotam da pretensão do indivíduo de preservar a autonomia e a peculiaridade de sua existência frente às superioridades da sociedade" (2005, p. 25). 
As condições de impessoalidade que caracterizam as ruas funcionam de modo a garantir que ali, frente a alguns estímulos, os transeuntes possam exercitar esse desejo de autonomia ocupando novos papéis. Uma grande passeata, um desfile de bloco de sujos, uma festa de torcida, uma peça teatral podem abrir espaços de jogo que permitem e estimulam os cidadãos a assumirem atitudes e papéis inesperados e deslocados de seus lugares no cotidiano.

O teatro que ocupa a rua e busca criar novos vetores no uso da rua pode ser uma força que agrega à rua novas imagens e ao mesmo tempo coloca o transeunte frente à oportunidade de ser partícipe dessa construção de imagens.

A cidade grande se define exatamente porque "a cada saída à rua, com a velocidade e as variedades da vida econômica, profissional e social" (SIMMEL, 2005) implica em experimentar a necessidade de se adaptar a uma intensa sobreposição de imagens o que constitui finalmente os próprios "fundamentos sensíveis da vida anímica, no quantum da consciência que [a cidade] nos exige em virtude de nossa organização" (SIMMEL, 2005).

Estas circunstâncias da cidade obrigam os sujeitos a construir estratégias de permanência e de identificação. Para Michel de Certeau o sujeito que a cidade abriga a re-fabrica para seu uso próprio buscando desmontar as correntes do aparato urbano para fazer prevalecer sua lei de consumo (1994). Nisso se inscrevem as dinâmicas que formulam estratégias e negociam com as diversas tramas que perfazem a cidade. Pensar o teatro na cidade desde esta perspectiva é lê-lo como uma trama que se sobrepõe a diversas tramas através de mediações e conflitos.

Kevin Lynch propõe pensar a cidade a partir da imagem que construímos da mesma. Antes de se pensar a cidade como elemento funcional, ou como projeto institucional, pensá-la a partir do olhar construtivo daqueles que a habitam, pois este olhar é também uma prática de construção e de definição das dinâmicas e sentidos da cidade. Buscando o intangível na conformação da imagem da cidade, Lynch identifica o valor dos elementos simbólicos para a formulação de uma noção de cidade que repercute diretamente nas dinâmicas dos usos dessa cidade.

O teatro de rua se inscreve nesse terreno e representa uma fala artística que nomeia inúmeras formas teatrais que tomam a silhueta da cidade e implicam na instalação de diversos modos de relacionamento com a cidade. Um teatro que ocupa a silhueta da cidade propõe a construção de novos lugares políticos para aqueles cidadãos usuários das ruas, praças e outros espaços públicos, por isso é importante refletir sobre essa modalidade teatral considerando a construção de espaços de convivência. 


\section{Urdimento}

Invadindo espaços da cidade um teatro de ocupação não vê a rua como um lugar hospitaleiro, senão que busca redefinir zonas, espaços e vínculos com o público, lutando contra a hostilidade dos elementos da rua. Este teatro sempre procura superar o ordenamento estabelecido que se caracteriza principalmente por dar funcionalidade à circulação de pessoas, de carros e de mercadoria. No entanto, a rua é um espaço polivalente e multifacético que surpreende pelas oportunidades e desafios que coloca para os artistas que buscam desbravar esse espaço público característico do universo urbano. Estar na rua não é simplesmente entrar em contato com aquele que seria o público natural de um teatro de rua, é sobretudo ocupar um espaço de adversidade e estabelecer formas de interlocução com uma ampla diversidade de sujeitos.

Quando os espetáculos teatrais de rua propõem ao transeunte um enfrentamento com linguagens e modos expressivos que vão além de modelos espetaculares facilmente reconhecíveis o que se estabelece é um exercício de desorganização dos procedimentos tradicionais de recepção do teatro na rua. Assim se abre um processo de criação de um novo jogo de relações que compromete a própria audiência tanto no desvendamento das regras do espetáculo como na leitura de como o espetáculo funciona dentro da estrutura das ruas.

Algumas experiências cênicas recentes permitem pensar sobre as hipóteses levantadas no presente texto:

O exemplo do espetáculo da companhia francesa Royal de Luxe, $A$ Pequena Gigante, no qual se faz transitar pelas ruas da cidade uma enorme marionete de uma menina que estabelece diferentes formas de contato com os cidadãos que fascinados seguem a delicada gigante pelas ruas, nos apresenta uma forma concreta de redefinir os sentidos da rua e propor modos diversos do uso da rua. Em Mitologias do Clã do grupo brasileiro Falus Stercus ${ }^{2}$, a exposição de corpos nus e os contatos eróticos que não excluem a participação eventual de alguém da audiência, criam tensões ao mesmo tempo em que atraem olhares e os mais diversos comentários, entre incomodados e excitados. Das Saborosas Aventuras de Dom Quixote de La Mancha e seu Fiel Escudeiro Sancho Pança do grupo Teatro que Roda ${ }^{3}$, rompendo os fluxos das ruas e convocando os espectadores a juntar-se aos atores desobedecendo os sinais de trânsito e a lógica do ir e vir, sugere a possibilidade de um novo lugar para os pedestres que podem, nas condições do espetáculo criar e se transformarem ainda que momentaneamente - em atores capazes de intervir decisivamente na construção da trama. Esse espetáculo ainda trabalha com uma noção de audiência funcional como uma ferramenta decisiva na articulação dos espaços cênicos que propõe a encenação a partir do conceito de dramaturgia da cidade. Em Flor de Um Dia da companhia argentina Escena Subterránea ${ }^{4}$ a construção do espetáculo com apenas quatro atores demanda um elenco muito

${ }^{2}$ Direção Jean Luc Courcoult.

3Direção André Carreira.

${ }^{4}$ Texto e direção de Martin Joab. 
mais numerosos que deve ser provido pelo próprio público que só poderá ver o espetáculo se intervir como ator e figurante redefinindo o espaço de uma praça como uma locação cinematográfica.

Todos estes espetáculos têm em comum o fato de que suas propostas cênicas implicam não apenas em alguma forma de intromissão no espaço sócio cultural das ruas, mas sobretudo na sugestão de novas formas de relacionamento dos transeuntes com a cidade e com os outros usuários da cidade. Isso se dá, necessariamente, de forma transitória. Nenhum espetáculo nestas condições pode ter a pretensão de instalar novas relações e vínculos de forma perene, mas pode supor que a intervenção cênica que abre oportunidades de que os cidadãos criativamente optem por assumir comportamentos que escapam à lógica tradicional discuta a noção de comunidade urbana.

Os diálogos que o teatro de rua - o teatro que ocupa a cidade - pretende estabelecer com o contexto urbano devem pressupor a existência de múltiplas formas híbridas da cultura da rua. Atuar nesta zona de imbricação de diferentes vetores culturais é também colocar em discussão as formas de relacionamento que predominam no espaço público das ruas e incluir novos elementos que cruzam transversalmente os modos de operação dos transeuntes, vendedores ambulantes, policiais, motoristas, passageiros de ônibus, moradores de rua.

Ocupar a rua é propor novas comunidades provisórias, comunidades baseadas no comportamento lúdico que não nasce da simples observação como espectador, mas sim da atitude do cidadão que decide mudar seu comportamento momentaneamente. Neste sentido, é oportuno dizer que o carnaval, festa que se baseia na convocatória para que o cidadão se faça folião e desfrute da folia como inversão da ordem do mundo, apresenta elementos que aparecem nos acontecimentos relacionados com um teatro de ocupação ainda que este último não tenha, logicamente, a força institucional daquela festa que mobiliza milhões de pessoas e somas consideráveis de recursos financeiros.

O teatro de ocupação não pode deixar de ver em seu projeto geral linhas de contato com a noção de festa no que diz respeito à desorganização da ordem institucional e a proposição de novos vínculos entre os realizadores e a audiência que superem a tradicional condição de audiência. Não se trata de maneira simplista de instituir formas ligeiras de participação, e muito menos de supor que tal participação por si só revista a importância de um elemento de transformação.

A ideia de criar condições para o estabelecimento de novos vínculos remete especialmente ao desejo de se fazer do acontecimento teatral um elemento vital interferindo no ambiente urbano. Essa interferência deverá necessariamente ter características ambientais, isto é, ser algo que deforme 
o projeto institucional que rege o funcionamento das ruas. $\mathrm{O}$ ambiente é consequência da ação dos sujeitos que utilizam o espaço da cidade, e este sempre se constrói em atrito com a ideia de projeto que busca ordenar, normatizar e planejar as ações e os usos coletivos. Aqui trabalho com a referência de Lynch que afirma que "o ambiente é a organização dos espaços reais de convivência e estruturação dos mecanismos das condições de vida" (2006). O ambiente é o resultado da intervenção cotidiana dos sujeitos e forças sociais no lugar. O ambiente é dinâmico e mutável, e ao mesmo tempo é condicionante e condicionado pela ação dos sujeitos sociais, tanto em dias dinâmicas coletivas como individuais. Este é cecorrente do contato e atrito das condições físicoestruturais com o repertório de uso dominante.

$\mathrm{O}$ ambiente se contrapõe ao projeto porque resulta das dinâmicas de uso e de resistência ao normatizado. E ainda que se possa afirmar que o projeto seja sempre uma quimera, pois a cidade como organismo vivo é um ambiente dinâmico em mutação, ao projetar e planejar o aparato institucional cria estruturas de coerção e ordenamento contra os quais as forças do uso cotidiano se enfrentam permanentemente.

O teatro de ocupação - uma dessas forças - deve perceber as lógicas institucionais e descobrir os espaços intersticiais como frestas através das quais introduzir propostas de comportamento que estimulem um novo olhar sobre a cidade. Olhar a cidade desde outra perspectiva que não a cotidiana e repetida é revisar o lugar de cada um dentro do mecanismo simbólico de poder inscrito na cidade.

Revisando nosso lugar na cidade estamos ao mesmo tempo instalando redes momentâneas de relações, acordos de compartilhamento e comunidades teatrais que duram enquanto está vivo o fugaz espetáculo do teatro.

A comunidade do teatro de ocupação estará conformada, necessariamente, pelos cidadãos e pelos atores no processo de utilização da cidade a partir de uma nova lógica. Neste momento a própria noção de tempo - tempo de circulação - estará ameaçada pela decisão de criar formas alternas de fruição da cidade. A comunidade que se pretende estabelecer será uma comunidade que se definirá pelo prazer do jogo teatral, pelo gozo de se observar ou de se protagonizar atritos entre o real e o ficcional. Desse modo o sujeito na rua estará ocupando o duplo lugar de usuário da cidade e espectador-ator de uma forma teatral que sempre funciona como uma microrruptura lúdica dos ritmos operacionais da urbe, ou de zonas dessa urbe.

A cidade como ambiente está composta de inúmeros espaços profundamente articulados, no entanto, seus segmentos constituem universos complexos que funcionam como zonas reconhecíveis pelos seus usuários. 
Estes espaços sobrepostos representam as figurações da cidade estabelecidas pelos usuários e também pelo campo institucional. Assim, para cada segmento existem múltiplas versões imaginadas, mas predomina a polaridade que se manifesta entre a imagem estabelecida pela instituição por um lado e por outro as imagens daqueles que transitam pelas ruas de modo diário.

A cidade estabelece, principalmente, através das dinâmicas de seus transeuntes verdadeiros circuitos de uso, e assim pode-se perceber que além da gestão ordenadora das instituições, sejam elas governamentais ou não, a cidade respeita também normatizações informais que tem durabilidade e que são fundamentais na hora de compreender sua estrutura ambiental.

O teatro de ocupação dialoga com estes dois níveis de "estruturação" da cidade. Por isso é interessante refletir sobre como dialogar com os labirintos estabelecidos pelos usuários, pois é neste terreno que se pode formular de modo mais intenso a possibilidade de organizar comunidades momentâneas. Penetrar o mundo dos labirintos invisíveis da cidade é de fato falar diretamente com um conjunto de sujeitos que compõe a matéria da cidade que caminha.

Dentro das estruturas culturais que estão nas ruas o teatro de ocupação pode adquirir maior potencia simbólica, pois interfere de modo direto na imagem da cidade imaginada como algo que não se apresenta como cotidiano. É essa condição extraordinária - no sentido mais simples do termo - que potencializa seu papel. Ao não pertencer naturalmente à rua, ao se fazer novidade, ao trazer o inesperado e muitas vezes desconhecido, para a rua o teatro de ocupação gera uma nova condição de recepção onde a presença do lúdico permite a fabricação de tramas de jogo mais livres.

Diferentemente dos grupos musicais, dos pastores, dos camelôs, dos malabaristas de sinais, das estátuas vivas, e do teatro de rua que conforma uma roda estática, aquelas formas teatrais que se pensam em processo de ocupação, não são imediatamente reconhecidas pelo público transeunte e demandam um tempo de decodificação, um processo de compreensão do jogo e ao mesmo tempo pedem que o público tome decisões que comprometem não apenas o tempo de seus compromissos imediatos, como também o seu corpo que deve se deslocar, se oferecer para a cena se expondo inclusive a uma certa quota de risco. Como em todo jogo os jogadores se colocam em risco ao se moverem buscando cumprir seus objetivos. Quando alguém decide seguir um espetáculo que se move pelo centro da cidade se transforma imediatamente em parte do espetáculo dado que haverá um grande número de cidadãos que permanecerá estático observando o grupo de atores e público em movimento como um espetáculo em si mesmo. Seguir, e muitas vezes interferir participando da trama da encenação representa construir o teatro como acontecimento 
cultural. Como afirma Marco De Marinis "o fazer teatral é também obra do espectador dado que sabemos que o teatro apenas pode existir dentro de uma relação na qual existem ao menos um ator e um espectador" (1995).

O desbravar a rua como um território adverso por meio de um teatro que ocupa a cidade será sempre um gesto que se politiza de forma imediata não apenas porque esse teatro se faz como elemento vincular da relação explicitada anteriormente, mas também porque o mesmo potencializa o atrito inevitável que existe entre as regras do ambiente e as falas artísticas que ocupam esse espaço formulando novas ordens, ainda que temporárias.

O aspecto político por excelência do teatro de ocupação não se refere em primeiro lugar ao trabalho com temas relacionados com conflitos políticos ou de reivindicações setoriais; em segundo lugar é preciso dizer que a convocação das pessoas para desobedecer às leis de trânsito (entre outras) já explicita como o lúdico pode ser instrumento de questionamento de estruturas de dominação.

O sociólogo francês, Jean Duvignaud, atribui ao jogo livre que se refere à criação de um "estado de ruptura do ser individual ou social onde a única coisa que não se questiona é a arte” (1982, p. 12), um papel central na nossa relação com a ordem estabelecida. Para Duvignaud esse jogo que dispõe livremente do espaço, do tempo e das formas e da matéria (1982, p.12) está relacionado com a hipótese do imaginário como insurreição contra o adormecimento dos homens e do mundo pelo cotidiano, pela rotina funcional.

Certamente, não se trata de fraturas nos sistemas hegemônicos ou mesmo rupturas fundamentais nas regras de funcionamento das ruas, mas sim nos processos que podem ser experimentados pelos cidadãos que vivenciam a inversão de lógica que a cena de ocupação busca promover. Como afirmei anteriormente, se somos capazes de reconhecer essa potência política da experiência do teatro na rua podemos nos desobrigar da busca dos cânones do teatro militante para poder constituir um acontecimento que se constitua em uma fala política exatamente porque interfere diretamente nas micropólis, nos circuitos de usos dos cidadãos. Dialogando assim muito mais com esferas segmentadas da cidade do que com suas amplas dimensões.

O que buscamos é o estabelecimento das comunidades breves que o teatro propõe quando ocupa as ruas das cidades. Comunidades que podem ser estabelecidas considerando mais que nada a interferência da experiência teatral nestes segmentos da cidade onde os indivíduos constroem identificações com suas cidades imaginadas.

Além dessa fala, que interfere diretamente sobre a noção de cidadão e espectador, esse teatro politiza a rua ao fazer visíveis comportamentos inusitados no quadro do ordenamento geral da cidade, e ao criar tensões com as regras da 
rua ainda que mais não seja de modo fugaz. A criação de ambientes lúdicos - ação fundamental do fenômeno teatral nas ruas - contribui para a que a cidade se faça - como diz Canclini "densa ao se encher de fantasias heterogêneas [pois] a urbe, programada para funcionar, desenhada em quadrícula, se transborda e se multiplica em ficções individuais e coletivas” (2005, p. 107). Se a cidade já se formula em ficções pela própria ação dos cidadãos, isso fica potencializado pela interferência do lúdico, já seja pela dinâmica de festas ou pela presença do teatro como propositor de experiências. O jogo que o teatro de rua propõe tem sempre o desejo de instaurar um novo lugar para o indivíduo dentro das regras da cidade. Isso pode não se dar na maioria das práticas, mas está sempre presente nos projetos que tomam a rua, pois buscam sempre redefinir a condição de recepção do evento teatral.

A rua é um espaço paradoxal onde se pode ver comportamentos extremos e contradições que o mundo das instituições evita. Portanto, ao ocupar o espaço da rua o teatro se aproxima a estas tensões, e desta forma se insere em um espaço de relações voláteis. Neste terreno movediço gerar uma abordagem cênica que mobilize os transeuntes de forma a constituir espaços de compartilhamento pode ser considerada uma ação fundamental da cena que toma a cidade.

A intensidade dos vínculos que se pode estabelecer no contexto fragmentário e fugaz da experiência de rua estará determinada tanto pelas condições objetivas do contexto da rua que atuam sobre espectadores e atores, como pela potencialidade das ações levadas a cabo pelos participantes do evento teatral. A comunidade fugaz nasce nos liames do jogo - de um jogo onde gente comum se permite atravessar fronteiras sociais e afetivas -, e o teatro de ocupação funciona como provocador desses atravessamentos porque sua condição de fala artística facilita o diálogo com um cotidiano de rotinas que sempre deriva o lúdico para o âmbito das festas rigidamente situadas no calendário.

\section{Referências bibliográficas}

CARREIRA, André. Teatro de invasão: redefinindo a ordem da cidade. In Espaço e Teatro (do edifício teatral à cidade como palco). LIMA, Evelyn Furquim Werneck (org.). Rio de Janeiro: Vozes/ 7 Letras, 2008.

. Teatro de rua como apropriação da silhueta urbana. Hibridismo e jogo no espaço inóspito. In: Revista Trans/Form/Ação. São Paulo, 24: 1-309, 2001.

CERTEAU, Michel. A Invenção do cotidiano. 2 ed. Petrópolis: Vozes, 1994.

DE MARINIS, Marco. Tener experiência del arte- Hacia uma revisión de las relaciones, Teoría y practica en el marco de la nueva teatrología. In: La puesta en escena en Latinoamérica: teoria y práctica teatral. PELLETIERI, Osvaldo (org.). Buenos Aires: Galerna, 1995. 
DUVignAUD, Jean. El juego del juego. México: Fondo de Cultura Económica, 1982.

FERRARA, Lucrecia D`Aléssio. Ver a cidade: cidade, imagem e leitura. São Paulo: Nobel, 1998.

GARCÍA CANCLINI, Nestor. Imaginarios Urbanos. Buenos Aires: Eudeba, 2005. LYNCH, Kevin. A imagem da cidade. Trad. Jeffer Luiz Camargo. São Paulo: Martins Fontes, 2006.

SIMMEL, Georg. As grandes cidades e a vida do espirito. In: Mana v.1 1, n.2, Rio de Janeiro, out. 2005. 